\title{
Evaluation of oviposition traps as an entomological surveillance method for Aedes aegypti (Diptera, Culicidae)
}

\author{
Angelita Anália Carniel Barbosa ${ }^{1}$, Eliane Aparecida Fávaro ${ }^{1}$, Adriano Mondini ${ }^{1}$, Margareth Regina Dibo ${ }^{1,2}$ \\ \& Francisco Chiaravalloti Neto ${ }^{3}$
}

${ }^{1}$ Faculdade de Medicina de São José do Rio Preto. Av. Brigadeiro Faria Lima, 5416 - São Pedro, 15090000 São José do Rio Preto-SP, Brasil. angelita_carniel@yahoo.com.br

${ }^{2}$ SUCEN: Superintendência de Controle de Endemias. medibo@famerp.br

${ }^{3}$ FSP-USP: Faculdade de Saúde Pública da USP. Av. Dr. Arnaldo, 715, 01246-904 São Paulo-SP, Brasil. franciscochiara@usp.br

\begin{abstract}
Evaluation of oviposition traps as an entomological surveillance method for Aedes aegypti (Diptera, Culicidae). This study aimed to describe the behavior of oviposition traps for Aedes aegypti over time, to compare it with the larval survey and to investigate the association with climatic variables. It was conducted in São José do Rio Preto city, São Paulo. Daily climatic data and fortnightly measurements for oviposition traps and larval infestation were collected from October 2003 to September 2004. Three different periods were identified in the behavior of oviposition traps' positivity and mean number of eggs: increase, plateau and decrease in values. These measurements followed the variation of climatic data from the first and third periods. High correlation was obtained between the positivity and the mean number of eggs. The oviposition traps showed higher capacity to detect the vector than did larval survey. It was observed that the first (October to December) and third (May to September) periods were considered to be the most suitable to use oviposition traps than larval surveys.
\end{abstract}

KEYWORDS. Dengue vector; egg collection; larval survey; mosquitoes.

RESUMO. Avaliação das armadilhas de oviposição como método de vigilância entomológica para Aedes aegypti (Diptera, Culicidae). O estudo teve como objetivos descrever o comportamento da armadilha de oviposição para Aedes aegypti ao longo do tempo, comparar com a pesquisa larvária e investigar sua associação com variáveis climáticas. O trabalho foi realizado em São José do Rio Preto, São Paulo. Entre outubro de 2003 a setembro de 2004, as armadilhas e a pesquisa larvária forneceram dados quinzenais e foram obtidos dados climáticos. Três períodos distintos foram identificados no comportamento da positividade das armadilhas e no número médio de ovos: aumento, patamar e decréscimo dos valores. Estas medidas acompanharam as variações climáticas. Alta correlação foi obtida entre a positividade e número de ovos. As armadilhas de oviposição apresentam maior capacidade para detectar o vetor do que a pesquisa larvária. Foi observado que o primeiro (outubro a dezembro) e terceiro (maio a setembro) períodos foram os mais adequados para utilização das armadilhas de oviposição em comparação à pesquisa larvária.

PALAVRAS-CHAVE. Coleta de ovos; dengue; mosquitos; pesquisa larvária.

Aedes (Stegomyia) aegypti (Linnaeus, 1762) is considered to be the main vector of dengue virus, an infectious disease which is increasingly more common all over the world (WHO 2002). Due to its high capacity to spread and adapt, surveillance strategies for the vector are complex. Thus, it is important to develop sensitive methods capable of identifying the presence of the vector, measuring its density and correlating this with the risk of dengue transmission (Morato et al. 2005; Focks 2003).

Fay \& Perry (1965) and Fay \& Eliason (1966) used oviposition traps for adult Ae. aegypti population surveillance, but the dengue control programs in Brazil do not consider the oviposition trap to be an effective method as it is not applied in routine activities (MS 2002). However, the use of other indicators, apart from the ones routinely employed, deserves special attention. It is also important to verify the best period for the use of each methodology throughout the year. Thus, this study aimed at describing the behavior of indices originating from oviposition traps, comparing them with, larval survey and looking for association whit climatic variables during a one-year period.

São José do Rio Preto is located in the northwestern region of the state of São Paulo (20 49' $11^{\prime}$ "South and 49 22' 11" West). The city is in a tropical region, with an average annual temperature of $25^{\circ} \mathrm{C}$ and annual rainfall of around 1,200 mm. The calculated sample size was 254 houses, considering a $10 \%$ positivity for Ae. aegypti, a precision of $3.5 \%$ and an alpha error of $5 \%$ for the larval survey, and it was increased to 423 houses, due to an expected proportion of $40 \%$ of closed houses. An expected positivity of $50 \%$, a precision of $10 \%$ and an alpha error of $5 \%$ were considered to calculate the number of oviposition traps, thus reaching a sample size of 100 traps.

A 50-block area containing 1,700 one-storey houses was chosen for trap installation. Two houses in each block were chosen and the traps were then installed, alternating north/ 
south and east/west facing houses. Other 26 blocks were chosen around this area, totaling 76 blocks with 2,500 houses, where larval surveys were taken.

The oviposition trap (Fay \& Eliason 1966), with a $12 \mathrm{~cm}$ x $2 \mathrm{~cm}$ thin plywood sheet placed inside, were installed in the open, around the houses, and at a height that ranged from $0.5 \mathrm{~m}$ to $1.0 \mathrm{~m}$. The field and laboratory activities started in the first week of October 2003 and lasted 12 months. The work with the oviposition traps was developed in two-week cycles. The traps were installed in the first week of each cycle and removed seven days after the installation, always in the same houses. The thin plywood sheets were individually packed in plastic bags and taken to the laboratory for egg counting. The eggs were not hatched, as Dibo et al. (2005) verified 99.2\% (95\% CI: 98.9-99.5) are Ae. aegypti and 0,8\% (95\% CI: 0,5-1,1) are Aedes (Stegomyia) albopictus (Skuse, 1894) in Mirassol, a neighboring town, were the Aedes mosquito infestation characteristics are very similar to São José do Rio Preto.

Fortnightly larval surveys in the 76 blocks were carried out. Every two weeks and during the first one, a systematic, random selection of one house out of every six of every block was performed. Larval survey was subsequently made in these chosen homes. The larvae were preserved for future identification in laboratory by means of taxonomic keys (Console \& Lourenço-de-Oliveira 1994).

The information on mean temperatures were provided by the Divisão Regional Agrícola de São José do Rio Preto da Secretária da Agricultura do Estado de São Paulo Regional. The mean humidity levels were provided by São José do Rio Preto's airport. Rainfall was measured every day at 6 am by a qualified professional. The daily mean temperatures, relative humidity and rainfall were grouped according to two-week cycles and stored.

The positivity of the traps, which is the number of sheets with egg(s) multiplied by 100 and divided by the total number of traps, and the number of eggs per trap, which is the total number of eggs divided by the total number of traps, were calculated for each fortnight. For each surveyed house the following information was recorded: number of containers with water and number of containers with Ae. aegypti larvae. The Breteau Index (BI), which is the number of containers with Ae. aegypti larvae per 100 surveyed houses (Breteau 1954), was calculated for each fortnight using the database.

The Spearman correlation coefficient was used to evaluate the existence of a correlation among the resulting measurements. Coefficients for the following situations were calculated: positivity and number of eggs in oviposition traps; positivity of oviposition traps and positivity of larval surveys; number of eggs in oviposition traps and BI. The agreement between the larval survey and oviposition trap was calculated by means of the non-parametric McNemar test. Calculations were made by pairing information per block and fortnightly. A certain block was considered positive for larval survey when Ae. aegypti larvae were found in one of the surveyed houses, and positive for the oviposition trap when there were eggs in at least one of the two installed traps.

To better understand the behaviour over a period of time

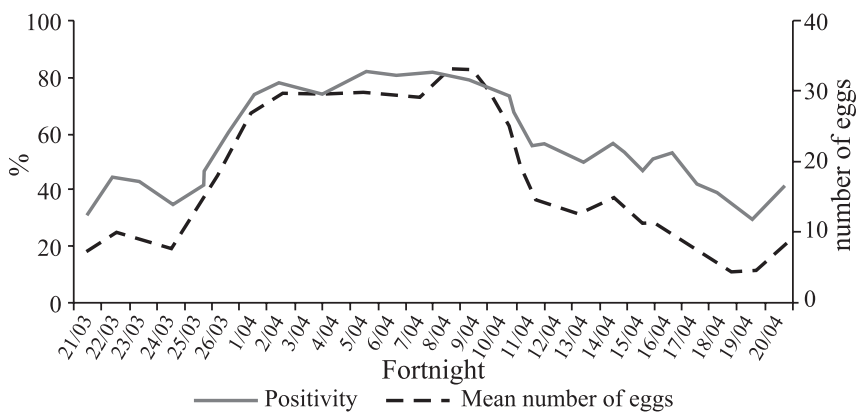

Fig. 1. Positivity and mean number of eggs according to fortnights, São José do Rio Preto, São Paulo - Brazil, October/2003 - September/2004. In these curves, the values are represented as mobile averages.

and to eliminate part of the random variation in positivity and mean number of eggs, they are shown in curves whose fortnightly values correspond to mobile averages with three values (the current fortnight, the previous fortnight, and the subsequent fortnight) (Figure 1). The curves showed similar distributions over time. Three distinct periods of positivity curves can be identified. The first is in fortnights 21-26/03 (October-December), in which the values varied from 20\% to $60 \%$; the second is in fortnights 1-10/04 (January-May), in which the values were within the $60 \%$ to $80 \%$ plateau; and the third is in fortnights 11-20/04 (May-September), in which the values were below $60 \%$ and tended to decrease. There is a similarity of behavior between the positivity and the curve of the mean number of eggs. The Spearman coefficient, calculated for the positivity and mean number of eggs, was $0.7496(\mathrm{p}=0.0000)$.

Figure 2A shows the distribution of the $\mathrm{BI}$ in relation to time. The curve of this index showed oscillations. The curve started to increase at the beginning and reached its highest point in the fortnight 2/04 (January), followed by a decrease and another increase with an intermediate peak in fortnights 10-11/04 (April-May). However, the BI decreased and showed null values in fortnights 16-18/04 (July-August), followed by new increase in fortnights 19-20/04 (September).

The comparison between the oviposition trap positivity curve and the BI curve reveals similarities in the initial (increase) fortnights (Figure 2A). The curves showed differences in intermediate fortnights; while the positivity varied within the $60 \%$ to $80 \%$ plateau, the BI oscillated from a maximum of 8.3 containers with Ae. aegypti larvae (5/04) to a minimum of 0.4 (2/04). In fortnight 5/04 (March), there was a great disagreement between these two measurements: while the positivity was $80.0 \%$, the BI was 0.4 . In the final period, the positivity and BI curves showed a tendency to decrease, but while the larval surveys did not detect the mosquito presence between the two-week periods 16 to 18/04 (JulyAugust), the positivity of traps was between 28.0 e $66.0 \%$.

The increase observed between fortnights 21/03 and 2/04 (October-January) for the positivity values, mean number of eggs and the BI coincided with the gradual increase in relative humidity and rainfall (Figure 2B). The decrease in rainfall in the fortnights 3-7/04 (February-March) did not influence the behavior of the positivity and the mean number of eggs, 
but seems to have influenced the BI values. The increase in rainfall in fortnights 8-11/04 (April-May) also influenced the BI values, which showed a relative peak in fortnights 1011/04 (May). There was a decline in temperature, relative humidity and rainfall in fortnights 8/04 and 12/04 (AprilJune), respectively. These changes may explain the decrease in the positivity and mean number of eggs noticed from fortnight 10/04 (May) and reduction in the BI from fortnight 12/04 (June). The increase in temperature from fortnight 16/04 (July) and rainfall and relative humidity in fortnights 19 and 20/04 (September) coincided with the appearance of BI values above zero (19-20/04) and increase in positivity and mean number of eggs (20/04).

The Spearman coefficient, calculated for the positivity of oviposition traps and the positivity of larval surveys, was 0.0581 ( $p=0.0361)$. For the mean number of eggs and BI, the value was 0.1035 ( $\mathrm{p}=0.0002)$. From the 1299 block paired, 88 (6.8\%) and 324 (24.9\%) were, respectively, positive and negative for the oviposition trap and larval surveys, 868 (66.8\%) were positive for oviposition trap survey and negative for larval survey, and 19 (1.5\%) were negative for oviposition trap survey and positive for larval survey. The McNemar test showed a highly significant result $(p<0.0001)$, thus indicating a disagreement between the two methods. Moreover, this revealed that oviposition traps showed higher capacity to detect the vector than did larval surveys, as the positivity of oviposition traps was 73.6\% (95\% CI: 71.176.0) and the positivy of larval survey (premise index) was 8.2\% (95\% CI: 6.8-9.9).

The coincidence of increase in the positivity and mean number of eggs from oviposition traps with the rise in rainfall and relative humidity through high temperatures, as found in our study, is comparable to reports from Tucson, Arizona, USA, (Hoeck et al. 2003) and from Argentina (Vezzani et al. 2004; Micieli \& Campos 2003; Stein et al. 2005). The decrease in oviposition, as seen in our study, was previously associated to a reduction in rainfall and/or temperature (Hoeck et al. 2003; Micieli \& Campos 2003; Vezzani et al. 2004; Stein et al. 2005). The occurrence of oviposition even in the driest months, as observed in São José do Rio Preto, in Salta Province, Argentina (Micieli \& Campos 2003) and Belo Horizonte, Brazil (Gama et al. 2007), is characteristic of tropical and subtropical zones, unlike what happens in temperate climate regions, where low temperatures in certain months of the year affect the mosquito population (Vezzani et al. 2004).

The good correlation between positivity and mean number of eggs was also reported by Dibo et al. (2005). Mogi et al. (1990) established a statistical relationship between the two measurements and indicated the possibility of estimating the number of eggs without counting them, a result that may be useful in areas where only Ae. aegypti eggs are detected on the polywood sheets (Dibo et al. 2005).

The reduced values of correlation coefficients between indicators originating from oviposition traps and those from larval surveys are in accordance with the differences noticed on the curves (Figure 2A). Furthermore, they show the lack of relationship between the quantity of eggs and the mosquito
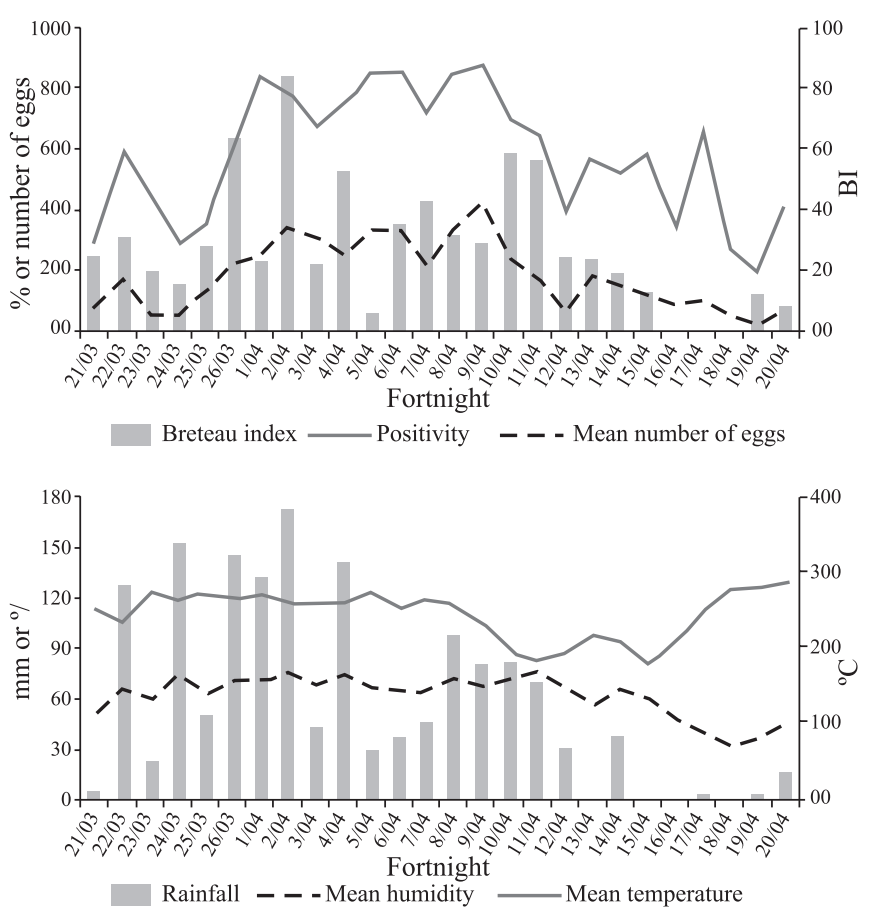

Fig. 2. (A) Positivity, mean number of eggs and Breteau Index (BI), and (B) temperature, relative humidity and rainfall according to fortnights, São José do Rio Preto, São Paulo - Brazil, October/ 2003 - September/2004.

population in the larval phase, due to a competition between traps and other breeding sites (Focks 2003). Similarly, Romero-Vivas \& Falconar (2005) did not find any significant correlation between the BI and the number of eggs in an urban area of Colombia.

The higher capacity of the oviposition traps to detect the presence of Ae. aegypti in relation to larval survey is in accordance with the results from several studies (Rawlins et al. 1998; Braga et al 2000; Morato et al. 2005; Romero-Vivas \& Falconar 2005; Gama et al. 2007). It is important to note that disagreements occurred between the two methods such as in the fortnights 5/04 and from 16 to 19/04. It is necessary to investigate when this characteristic may be used as a good entomological surveillance tool and contribute to direct vector control measures. For this reason, the three periods identified for positivity in our study may be considered: increase, plateau and decrease.

As regards the behavior of positivity and mean number of eggs in relation to the BI curve, differences were observed in the second period of the study: plateau with high positivity levels for the traps and oscillations and the occurrence of peak values for BI. As this is an index related to the presence of larvae, which depends on water in breeding containers, it must have been influenced by the variations in rainfall over the period. However, the oviposition traps lost their power as an entomological indicator when the majority of them became positive. Their best quality, which is to identify the presence of the vector, does not stand out, as there is a high availability of containers with water and/or mosquitoes and the traps, as a result, become just another breeding site.

The use of the BI as an entomological surveillance tool 
would be more interesting than the oviposition trap in the second period (January-May), as it gives an estimate of the number of positive breeding containers per area, provides data to prioritize areas with a higher quantity of containers with larvae, renders information on the type and importance of each breeding site, and enables the evaluation of control measures. On the other hand, the use of BI would not be indicated in the first and third periods as the lower values shown by the BI make its best feature lose importance or even disappear, because it has a lower capacity to detect the presence of the vector, as well as a higher operational cost than the oviposition trap (Focks 2003).

Apart from the reasons that justify the use of $\mathrm{BI}$ in the second period, it is important to note that it is not considered a good tool for entomological surveillance because it does not measure the containers productivity and does not have a clear association with dengue (Focks 2003; Tun-Lin et al. 1995). Other measures are under consideration, such as the number of pupae per person (Focks 2003), the egg density index (Regis et al. 2008), and the index based on sticky traps (Fávaro et al. 2008).

The use of oviposition traps would be more interesting in the first (October-December) and third (May to September) periods, because they are an ideal tool when larval measurements do not reveal the vector presence, or reveal it with lower intensity (Rawlins et al. 1998; Focks 2003; Morato et al. 2005). Their use would enable, at a much lower cost than the larval survey, the identification of vector presence sites that need to be prioritized, when adopting control measures in the periods with less rainfall and/or lower temperatures. During periods when adult mosquitoes are less present, the elimination of containers directed to areas with positive traps could contribute to slow down the increase in mosquito population in the period with more rainfall and high temperatures, thus decreasing the risk of dengue transmission.

\section{REFERENCES}

Braga, I. A.; A. C. Gomes; M. Nelson; R. C. G. Mello; D. P. Bergamaschi \& J. M. P. Souza. 2000. Comparação entre pesquisa larvária e armadilha de oviposição, para deteç̧ão de Aedes aegypti. Revista da Sociedade Brasileira Medicina Tropical 33: 347-353.

Breteau, H. 1954. La fièvre jaune em Afrique Óccidentale Française. Um aspect de la médicine préventive massive. Bulletin of the World Health Organization 11: 453-481.

Consoli, R. A. G. B. \& R. Lourenço-de-Oliveira. 1994. Principais mosquitos de importância sanitária no Brasil. Rio de Janeiro, Fiocruz, 225 p.

Dibo, M. R.; F. Chiaravalloti-Neto; M. Batigaglia; A. Mondini; E. A. Fávaro; A. A. C. Barbosa \& C. M. Glasser. 2005. Identification of the best ovitrap installation sites for gravid Aedes (Stegomya) aegypti in residences in Mirassol, state of São Paulo, Brazil. Memórias do Instituto Oswaldo Cruz 100: 339-343.

Fávaro, E. A.; A. Mondini; M. R. Dibo; A. A. C. Barbosa; A. E. Eiras \& F. Chiaravalloti-Neto. 2008. Assessment of entomological indicators of Aedes aegypti (L.) from adult and egg collections in São Paulo, Brazil. Journal of Vector Ecology 33: 8-16.

Fay, R. W. \& D. A. Eliason. 1966. A preferred oviposition site as a surveillance method for Aedes aegypti. Mosquitoes News 26: 531-535.

Fay, R. W. \& A. S. Perry. 1965. Laboratory studies of ovipositional preferences of Aedes aegypti. Mosquitoes News 25: 276-281.

Focks, D. A. 2003. A review of entomological sampling methods and indicators for dengue vectors. Gainsville, World Health Organization, $40 \mathrm{p}$.

Gama, R. A.; E. M. Silva; I. M. Silva; M. C. Resende \& A. E. Eiras. 2007. Evaluation of the sticky MosquiTRAP ${ }^{\mathrm{TM}}$ for detecting Aedes (Stegomyia) aegypti (L.) (Diptera: Culicidae) during the dry season in Belo Horizonte, Minas Gerais, Brasil. Neotropical Entomology 36: 294-302.

Hoeck, P. A. E.; F. B. Ramberg; S. A. Merill; C. Moll \& H. H. Hagedorn. 2003. Population and parity levels of Aedes aegypti collected in Tucson. Journal of Vector Ecology 28: 65-73.

Micieli, M. V. \& R. E. Campos. 2003. Oviposition activity and seasonal pattern of a population of Aedes (Stegomya) aegypti (L.) (Diptera: Culicidae) in subtropical Argentina. Memórias do Instituto Oswaldo Cruz 98: 659-63.

Mogi, M.; W. Choochote; C. Khamboonruang \& P. Suwanoanit. 1990. Applicability of presence-absence and sequential sampling for ovitrap surveillance of Aedes (Diptera: Culicidae) in Chang Mai, Northern Thailand. Journal of Medical Entomology 27: 509-514.

Morato, V. C. G.; M. G. Teixeira; A. C. Gomes; D. P. Bergamaschi \& M. L. Barreto. 2005. Infestation of Aedes aegypti estimated by oviposition traps in Brazil. Revista de Saúde Pública 39: 553-558.

MS - Ministério da Saúde. 2002. Fundação Nacional de Saúde, Programa Nacional de Controle da Dengue. Ministério da Saúde, Brasília, 32 p.

Rawlins, S. C.; R. Martinez; S. Wiltshire \& G. Legall. 1998. A comparison of surveillance systems for the dengue vector Aedes aegypti in Port of Spain, Trinidad. Journal of the American Mosquitoes Control Association 14: 131-136.

Regis, L.; A. M. Monteiro; M. A. V. Melo-Santos; J. C. Silveira; A. F. Furtado; R. V. Acioli; G. M. Santos; M. Nakazawa; M. S. Carvalho; P. J. Ribeiro Jr \& W. V. Souza. 2008. Developing new approaches for detecting and preventing Aedes aegypti population outbreaks: basis for surveillance, alert and control system. Memórias do Instituto Oswaldo Cruz 103: 50-59.

Romero-Vivas, C. M. \& A. K. I. Falconar. 2005. Investigation of relationships between Aedes aegypti egg, larvae, pupae, and adult density indices where their main breeding sites were located indoors. Journal of the American Mosquitoes Control Association 21: 15-21.

Stein, M.; G. I. Oria; W. R. Almirón \& J. A. Willener. 2005. Fluctuación estacional de Aedes aegypti in Chaco Province, Argentina. Revista de Saúde Pública 39: 559-564.

Tun-Lin, W.; B. H. Kay \& A. Barnes. 1995. Understanding productivity, a key to Aedes aegypti surveillance. American Journal of Tropical Medical Hygiene 53: 595-601.

Vezzani, D.; S. M. Velázquez \& N. Schweigmann. 2004. Seasonal pattern of abundance of Aedes aegypti (Díptera: Culicidae) in Buenos Aires City, Argentina. Memórias do Instituto Oswaldo Cruz 99: 351-356.

WHO-World Health Organization. 2002. Dengue and dengue haemorrhagic fever. Fact Sheet n ${ }^{\circ} 117$. Geneva, World Health Organization. 